Meta

Journal des traducteurs

Translators' Journal

\title{
Voyages via paysages littéraires traduits : la littérature canadienne en Bulgarie (lectures et absences)
}

\section{Slav Ognyanov Petkov}

Volume 60, numéro 2, août 2015

$60^{\mathrm{e}}$ anniversaire. Les horizons de la traduction : retour vers le futur $60^{\text {th }}$ Anniversary. Translation's Horizons: Back to the Future

60mo aniversario. Los horizontes de la traducción: regreso al futuro

URI : https://id.erudit.org/iderudit/1032913ar

DOI : https://doi.org/10.7202/1032913ar

Aller au sommaire du numéro

Éditeur(s)

Les Presses de l’Université de Montréal

ISSN

0026-0452 (imprimé)

1492-1421 (numérique)

Découvrir la revue

Citer ce document

Petkov, S. O. (2015). Voyages via paysages littéraires traduits : la littérature canadienne en Bulgarie (lectures et absences). Meta, 60(2), 362-362.

https://doi.org/10.7202/1032913ar 


\title{
Voyages via paysages littéraires traduits: la littérature canadienne en Bulgarie (lectures et absences)
}

\author{
Slav Ognyanov Petkov \\ Université de Plovdiv «Paisssii Hilendarski», Plovdiv, Bulgarie \\ slav.petkov@aol.com
}

Pour beaucoup de Bulgares, le Canada représente non seulement un pays de paix et de beauté, mais aussi un rêve. Or, très peu connaissent la littérature et la culture canadiennes. Notre but tout au long de cette présentation est de dresser un bilan sur les lettres canadiennes en Bulgarie, en tant que porteuses d'altérités de l'Amérique du Nord. Nous allons voir ce qu'il y a comme œuvres canadiennes traduites dans quelques bibliothèques bulgares; cela va nous permettre de lancer des réflexions sur le pourquoi des choix de traduire des textes donnés plutôt que d'autres. Une analyse de la situation s'imposera sans aucun doute. Dans un second temps, nous orienterons notre attention sur la traduction de réalités canadiennes (québécoises surtout) dans des textes sélectionnés. Cela va nous pousser à l'élaboration d'une image bien réelle de la présence du Canada en Bulgarie.

Membre de l'Association canadienne de traductologie, de la Société des professeurs français et francophones d'Amérique et du Cercle d'or, Slav Petkov est diplômé de l'Université de Sofia «Saint Clément d'Ohrid» (licence de philologie française en 2009; master d'études sur les Francophonies en 2011). Il a commencé à travailler sur les aspects socioculturels de la traduction en 2013 quand il est devenu doctorant à l'Université de Plovdiv «Paissii Hilendarski » (Département d'études romanes et germaniques). Ses intérêts sont liés aux relations entre la culture et la langue lors de la traduction en tant que processus, et aux Études francophones (le Québec, le Luxembourg et la Suisse, surtout). 